\title{
Hierarchical Decision-Making in the Factory of the Future
}

Richard H. F. Jackson, Albert W. T. Jones

U.S. DEPARTMENT OF COMMERCE

National Bureau of Standards

National Engineering Laboratory

Center for Applied Mathematics

Gaithersburg, MD 20899

February 1987

A report for:

U.S. DEPARTMENT OF COMMERCE

$1-Q C \quad$ eau of Standards

$1100 \quad$ anufacturing Engineering

1. 1156 I, MD 20899

$87-3511$

1987

c. 2 

NBSIR $87-3511$

HIERARCHICAL DECISION-MAKING IN THE

FACTORY OF THE FUTURE

Richard H. F. Jackson, Albert W. T. Jones

U.S. DEPARTMENT OF COMMERCE

National Bureau of Standards

National Engineering Laboratory

Center for Applied Mathematics

Gaithersburg, MD 20899

February 1987

A report for:

U.S. DEPARTMENT OF COMMERCE

National Bureau of Standards

Center for Manufacturing Engineering

Gaithersburg, MD 20899

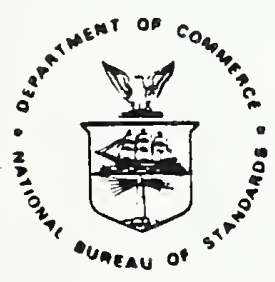

U.S. DEPARTMENT OF COMMERCE, Malcolm Baldrige, Secretary NATIONAL BUREAU OF STANDARDS. Ernest Ambler. Director 



\section{ABSTRACT}

A major manufacturing research facility is being established at the National Bureau of Standards. The Automated Manufacturing Research Facility will address the standards and measurement needs for the factory of the future. A five-layer hierachical control architecture is under development to manage all production and support activities within the facility. The proper execution of many of these activities requires the solution to one or more optimization problems. This paper describes a hierarchical planning architecture and the decision-making problems that exist at each level within that architecture.

\section{KEYWORDS :}

Automated Manufacturing, Factory Model, Flexible Manufacturing, Hierarchical Control, Real-time, Optimization, Scheduling, Routing.

\section{INTRODUCTION}

Manufacturing plants typically consist of combinations of people and machines, working together to maximize corporate profits from the goods they produce. Because of poor planning and scheduling strategies, most of these plants are plagued by large work-in-process inventories, low utilization of equipment, insufficient throughput, and excessive delays, all of which decrease profits. Hopes for alleviating these problems were raised when automated equipment such as industrial robots became commercially available and sophisticated computer technology was developed to support it. Many companies made large capital investments in these new technologies expecting that their integration into existing plants would increase their profits and improve their shares of the world markets.

This has not happened, and the problems have not disappeared. In fact, their presence in these integrated, automated environments tends to have a greater negative impact. It is not possible to increase profits or achieve the desired rate of return on capital investments when expensive equipment is idle because of poor planning and scheduling. In addition, because of the introduction of new equipment and new technologies in data management and communications, new problems have been discovered that did not exist before. Clearly, the need exists to:

o design better techniques for solving the old problems,

o identify and solve the new problems, and

o develop an integrated framework for solving all of them.

This paper describes the approach under development at the Nationai Bureau of Standards (NBS) to address these issues within the Automated Manufacturing Research Facility (AMRF) [1].

The remainder of this paper is composed of eight sections. After this introductory section, section 2 provides an overview of the AMRF, including the design philosophy used in building it, its decomposition into basic, hierachically connected components, and a description of each of these components. Section 3 describes some of the classical approaches to planning and scheduling, explains why these can no longer be used in the automated 
factory, and describes briefly a new approach which capitalizes on this hierarchical design. In section 4, we identify the decision problems that exist in the AMRF, organized along the same lines as the hierarchical breakdown described in section 2. A framework to integrate planning and control is discussed in section 5. In section 6, the problems of managing data in real-time to support the new structure are discussed. Conclusions are given and future work is outlined in section 7. References are provided in section 8 .

\section{THE AMRF}

\subsection{Overview}

The National Bureau of Standards has a fundamental commitment to promote the development of standards for automated manufacturing systems and to transfer technology to American industry. To meet this responsibility, the Center for Manufacturing Engineering at NBS has established an experimental test bed, the Automated Manufacturing Research Facility [1,4]. Industry, academia, and other government agencies have played an active role in this development effort through direct appropriations, equipment loans, and cooperative research programs.

Physically, the AMRF contains several robot-tended machining workstations, a cleaning and deburring station, an inspection station, a material handling system, factory control software, database managememt systems, and the communications support to tie it all together. Basic principles from physics, computer science, the behaviorial sciences, control theory, operations research, and engineering disciplines have been used to transform these individual components into a fully integrated, flexible, small batch manufacturing sytem (see Figure 1).

\subsection{Design Philosophy}

The AMRF is intended to exhibit a greater degree of flexibility and modularity than any currently available "flexible manufacturing system". To achieve these goals, the AMRF has adopted the following design philosophies concerning its control architecture. It is:

- partitioned into a functional hierarchy in which the control processes are completely data driven and communicate via NBSdeveloped hardware and software interfaces which are uniform throughout the AMRF,

o designed to respond in real-time to performance data obtained from machines equipped with sensors,

- implemented in a distributed computer environment using state-of-the-art techniques in softwaxe engineering and artificial intelligence. 


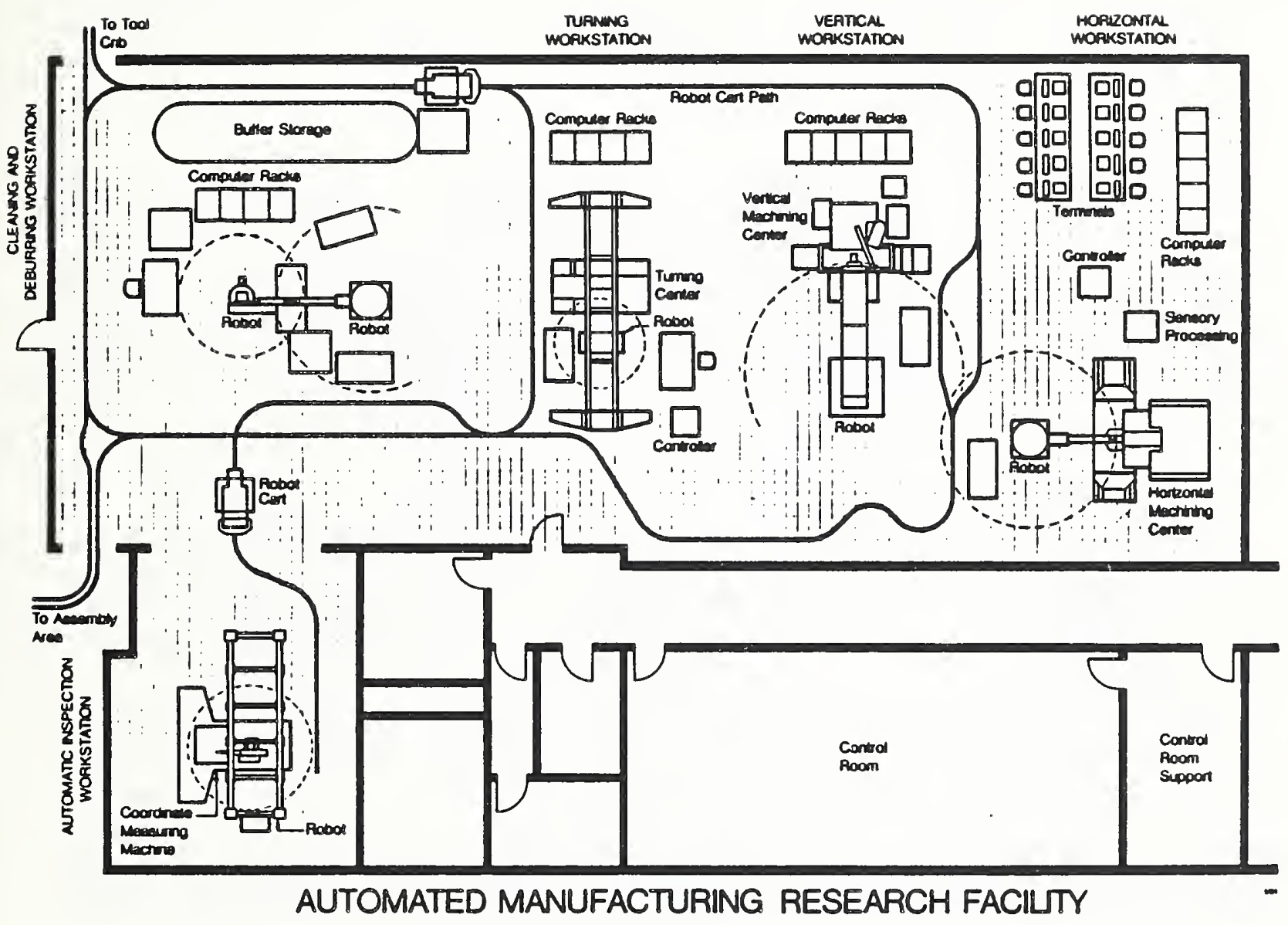

Figure 1. The Automated Manufacturing Research Facility. 
As noted above, the AMRF control architecture is based on the classic hierarchical, or tree-shaped, command/feedback control structure (see Figure 2) typical of many complex organizations [2-5]. This approach ensures that the size, functionality, and complexity of individual control modules is limited. Although the flow of control in this hierarchy is strictly vertical and between adjacent neighbors only, it is necessary and even desirable to share certain classes of data across one or more levels. In addition, each control level is completely data-driven. That is, the data required to perform its functions is separated from the actual control code. All data is managed by a distributed data administration system [11] and transmitted to and from control processes via a communication network that was designed to be compatible with the Manufacturing Automation Protocols (MAP) [12], but has not been fully implemented at this writing.

\subsection{Functional Decomposition}

An analysis $[1,4]$ of traditional small batch manufacturing systems provided the foundation for the decomposition of the control functions into five levels: facility, shop, cell, workstation, and equipment. Activity at each of these levels is data-driven, and each can be expanded to yield a more traditional, tree-like hierarchy as depicted in Figure 2. This structure provides a convenient mechanism for describing the functions of the automated facility and the databases needed to meet manufacturing requirements. This discussion is given next.

\subsubsection{Facility Leve1}

At this highest level are implemented the "front office" functions that are typically found in small batch manufacturing facilities. Activities at this level are grouped into subsystems that fall into three major functional areas: manufacturing engineering, information management, and production management.

Manufacturing engineering functions are typically carried out with human involvement via user-data interfaces. This includes computer-aided design (CAD), Group Technology Classification, and process planning. The information management activities provide user-data interfaces to support necessary administrative or business management functions. Production management tracks major projects, generates long-range schedules, identifies production resource requirements, determines the need for additional capital investments to meet production goals, determines excess production capacity, and summarizes quality performance data $[2,8]$.

\subsubsection{Shop Level}

This level is responsible for coordinating the production and support jobs on the shop floor $[2,8]$. It is also responsible for the allocation of resources to those jobs. Two major component modules have been identified within shop control: a task manager and a resource manager. 


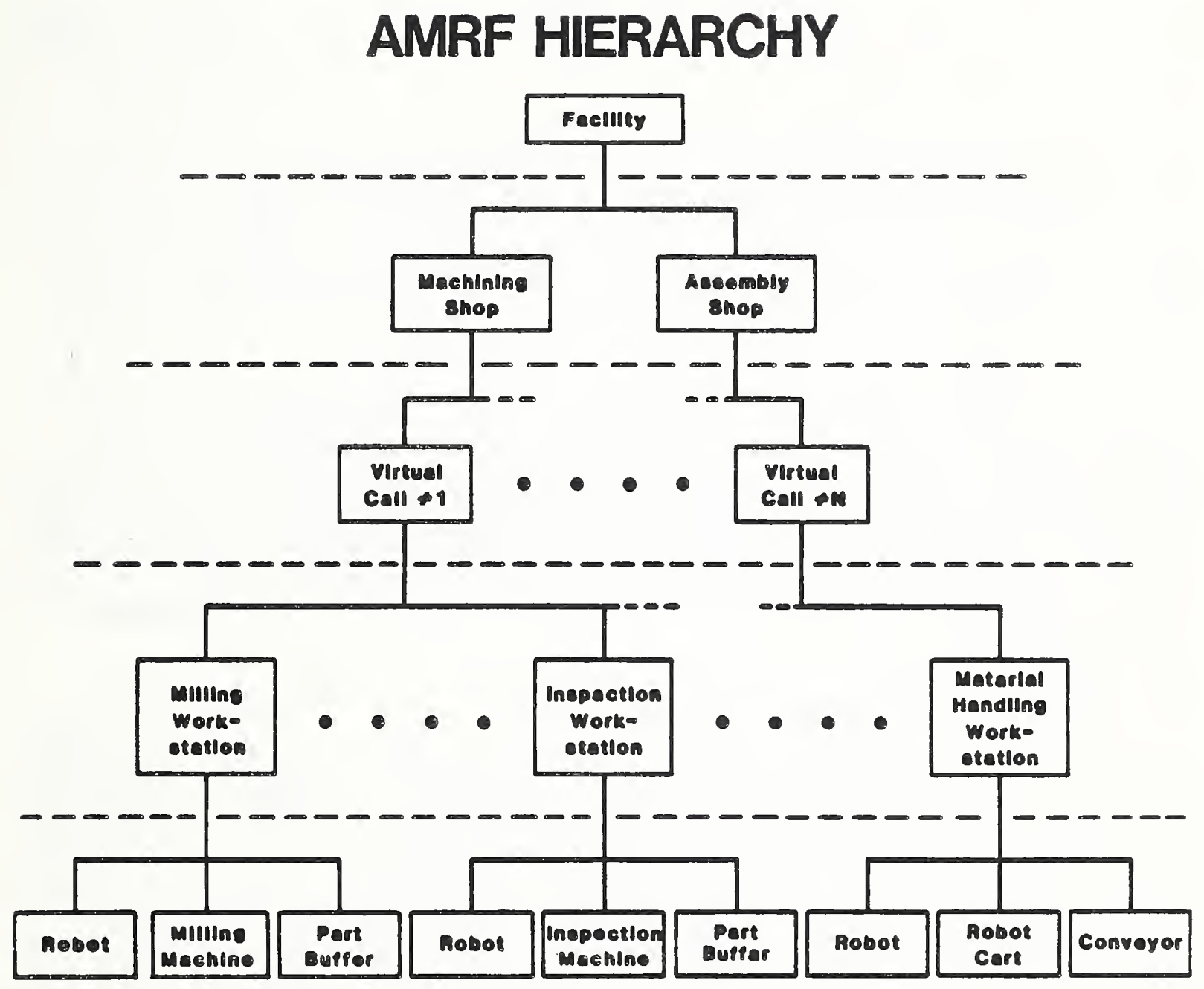

Figure 2. Expanded AMRF Control Hierarchy. 
The task managex of the shop level system is responsible for capacity planning, grouping orders into batches, assigning and releasing batch jobs to cells, and tracking individual orders to completion. The resource manager is responsible for allocating the production resources to individual cells, managing the repair of existing resources, and ordering new resources.

\subsubsection{Cell Level}

At this level, batch jobs of similar parts are sequenced through workstations and supervision is provided for various other support services, such as material handling and calibration. The cell [7] brings some of the efficiency of a flow shop to small batch production by using a set of machine tools and shared job setups to produce a family of similar parts. The AMRF cells are dynamic production control structures which permit the time sharing of workstation level processing systems. This software structure was named the "virtual" cell to distinguish it from previous "real" manufacturing cells which are defined by fixed groupings of equipment or machinery on the shop floor. A detailed discussion of the virtual cell concept is found in [6].

\subsubsection{Workstation Leve1}

The activities of small integrated physical groupings of shop floor equipment are directed and coordinated at the workstation leve1 [2,8]. A typical AMRF workstation consists of a robot, a machine tool, a material storage buffer and a control computer. Machining workstations process trays of parts that are delivered by the material handling system. The controller sequences equipment level subsystems through job setup, part fixturing, cutting processes, chip removal, in-process inspection, job takedown, and cleanup operations.

\subsubsection{Equipment Level}

These are "front-end" systems that are closely tied to commercial equipment or industrial machinery on the shop floor. Equipment controllers $[2,8]$ are required for robots, computer numerical control (CNC) machine tools, coordinate measuring machines, delivery systems, and storage/retrieval devices. The functions of the equipment controller are to translate the commands from the workstation controller into a sequence of simple tasks that can be understood by the vendor-supplied controller and to monitor the execution of these tasks via the sensors attached to the hardware. These controllers will be required for "off-the-shelf" equipment to provide extended functionality and compatibility with NBS control. concepts, until higher level front-ends are incorporated by system vendors. 


\section{APPROACHES TO PLANNING AND SCHEDULING PROBLEMS.}

In the preceding sections, the intent was to convey an appreciation of the benefits of hierarchical decomposition of the control problems within automated manufacturing facilities. The question addressed in the remainder of this paper is: Is it possible to mimic this hierarchical approach to control and decompose the planning process along the same lines described above for the facility as a whole? Before answering this question, we present a brief review of some other approaches.

\subsection{Classical Approaches}

Traditionally, planning and scheduling problems have been analyzed without decomposing them into subproblems [13-15]. The literature abounds with mathematical programming, simulation, heuristic, and other techniques for solving these problems under special conditions. Because of their computational requirements and restrictive assumptions, these approaches tend to have limited applicability in a real manufacturing environment. They are typically unable to provide useful solutions in a timely manner. It is hoped that the hierarchical approach described here will provide the mechanism for solving these problems in the timely and efficient manner required.

Since this is not a survey paper, no attempt is made here to provide a full review of the literature in these areas. For more information on the state-of-the-art in these traditional approaches, we direct the reader to some of the already existing, and well-done, literature reviews [24-27], or to the conference proceedings that are also available [34].

\subsection{Recent Advances}

In practice, planners and decision makers always decompose their difficult problems into subproblems. Typically, these subproblems are then given to experts to solve, and the decision maker must combine these individual solutions to obtain the solution to the original problem. Researchers [28-33] have recently begun to use concepts from Artificial Intelligence (AI) to attack these planning and scheduling problems in precisely this manner, with little success to date. Other researchers [1623] have combined AI techniques with the principles of hierarchical control to address some of these problems, but results have been limited to two levels of hierarchy. No one to our knowledge has attempted to develop an integrated framework which addresses all of the planning and scheduling problems in an automated manufacturing system.

\subsection{A New Approach}

This paper expands the control hierarchy described above into a goal-directed hierarchy in which both planning and control functions are carried out at every level. The amount of computation that can be performed in real-time at each level is limited by the planning horizon: the period of time over which the module is responsible for planning and updating local goals. These goals must be consistent with those set by the module's supervisor and they must commit the entire subordinate structure to a unified and coordinated course of action. This course of action, if successfully 
completed, should result in all goals being achieved. In pursuit of these goals, each module decomposes the input commands (see section 5.2.2) from its supervisor into procedures to be executed at that level and subcommands to be issued to one or more subordinate modules (see Figure 3). This decomposition process is repeated until, at the lowest level, a sequence of coordinated primitive actions is generated which actuates shop floor equipment [10]. The status feedback (see section 5.2.2) that is provided to supervisors by their subordinates, is used to close the control loop and support adaptive, real-time, decision making at each level.

\section{REAL-TIME DECISION PROBLEMS}

In this section, we identify the real-time decision problems that exist in the AMRF, which we believe are representative of those to be found in any automated manufacturing facility. The discussion is organized according to the five-level hierarchy of manufacturing system functions described above. What follows is, in a sense, a laundry list of problems, some classical and well-recognized, others new, arising from the introduction of new technologies into manufacturing systems. Indeed, some of the problems may seem insignificant now, but as automated systems become more sophisticated, the marginal gain from having optimal solutions to these problems could become extremely significant.

\subsection{Equipment Level}

The first level to be discussed is the equipment level, the lowest level in the hierarchy. The general rule for this level is that once a piece of equipment is instructed to do something, it must determine how best to perform it. The equipment on the shop floor is basically of two types: robots and machine tools served by the robots. In addition, we have separated the automated storage and retrieval system into a third category because of its special activities. All three catagories are discussed below.

\subsubsection{Robots}

The mathematical decision problems to be addressed at the equipment level include path generation, optimal routing for traversing parts for inspection, sequencing of tasks or activities with priorities, and loading, unloading, and layout of parts and tool trays.

Sequencing prioritized activities is an area where much is already known. The literature is extensive on the single machine scheduling, or sequencing, problem. In the automated manufacturing arena, the challenge is to solve these problems in real time, and in such a way that the schedule can be changed as often as desired when conditions change. There has been some work on this. See, e.g., [25]. 


\section{CONTROL FLOW}

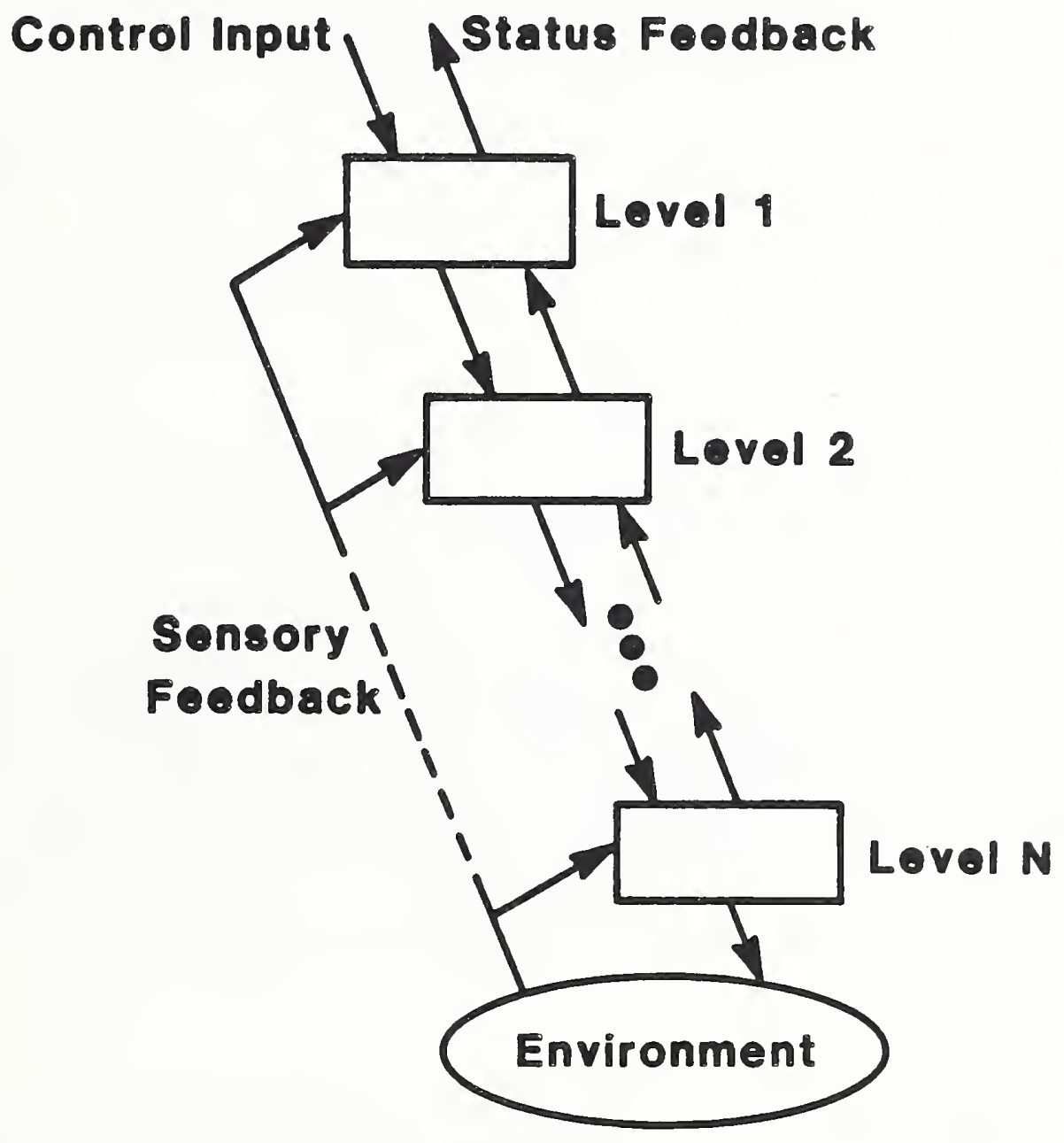

Figure 3. Control System Hierarchy. 
The inspection robots and the cleaning and deburring robots both require paths to be generated for the movement of their arms and hands. These, of course, should be optimal paths; e.g., shortest, longest, fastest, or cheapest depending on the situation. In fact, in some cases optimality may not be appropriate and should be replaced with a sub-optimal, yet feasible and easily generated path. Obstacle avoidance techniques must be included in this effort also.

Another area where optimization methods can be brought to bear is in the loading, unloading and layout of trays of parts and tools. Portions of this are facility layout problems, thus some of the ideas from the facility layout and design literature could be useful. The problems can be complicated by the possibility that multiple geometries may exist in the same tray.

There is an interesting optimization problem concerned with finding optimal routes for traversing parts for inspection, cleaning, and deburring. The objective is to perform these activities in a way that is optimal with respect to some measure, perhaps time, number of two-handed moves, or number of reconfigurations such as end-effector (e.g., gripper, assembly tool, cleaning and deburring tool) changes or part repositionings.

Another problem area is in the precise positioning of robot arms at the end of a path. This is an important problem and could be viewed as a solution to a nonlinear optimization problem in which the objective is to minimize the error in the actual position.

Pattern matching for robot vision systems is another area where significant optimization problems appear. These range from simple nonlinear least squares problems that arise from attempting to match patterns, to nonlinear least squares problems that arise in combining small windows of bit patterns to form larger windows for faster scanning.

The robot carts that serve the workstations must address some of the same problems as the fixed-position robots; they may, however, take on a slightly different look. For example, path calculations for the robots become routing problems for the carts. The issue here is deciding which path to take to deliver or pick up trays from the workstations. If the cart can travel forward and backward, the problem becomes more complicated. The situation is further complicated by having multiple carts, although the coordination activity for this is performed at the next higher level. The layout of the wire-guided path is also a task that lends itself to mathematical analysis and could be studied to determine the best paths to lay down.

\subsubsection{Machine Tools}

The decision problems that exist for machine tools are similar to those described above for robots. Perhaps principal among these is the scheduling of all activities and sub-activities that occur. Examples of these schedulable activities are tool changes, refixturings, chip removal, coolant spraying, and general housekeeping. The schedule should be optimal with respect to some performance measure, such as number of tool changes, number of refixturings, time in queue, or number of late tasks.

Also associated with the machine tool is the layout problem of determining the optimal placement of tools in the tool drum. An obvious application of optimization techniques related to this problem is minimizing the number of tools required for performing a given sequence of operations. 
Included here, too, is the problem of deciding which tools on hand should be kept for later jobs and which should be sent for storage elsewhere.

Just as in the case of the industrial robots above, tool path calculations are required for these machine tools. Lastly, there is the problem of developing diagnostics for tool wear and determining how and when to recover from errors.

\subsubsection{Automated Storage and Retrieval System}

The automated storage and retrieval sytem has basically two decision problems that must be addressed. The first is determining optimal buffer sizes for all buffer storage areas. The second problem is concerned with the layout of the storage areas. In this latter case, the objective is to store all the parts and tools required for a given task together in one or more contiguous storage bins. Of course, this is difficult to accomplish since storage areas are required and released frequently, leaving available portions spread throughout the storage bin area. This is a problem in dynamic storage allocation and planning for storage needs. Its solution would have consequences for the time required to transfer these items to the workstation for processing.

\subsection{Workstation Leve1}

In general, most of the same kinds of problems that appear at the equipment level appear also at the workstation level, with the additional problem of coordination of sub-activities at the equipment level.

\subsubsection{Material Handling}

For the material handling workstation, the first priority task is to decide the sequence in which to perform the tasks assigned to it. In the case of multiple carts, decisions must be made about which cart to be assigned to which task. Then, an optimal routing for the cart(s) must be computed. Lastly, all these activities must be coordinated and monitored for possible changes and updates.

Also to be coordinated by this workstation is the storage and retrieval of equipment at the workstation and at the inventory workstation (warehouse). Planning is required here to minimize the number of stores and retrieves required to perform a task, while restricting the size of local buffers.

Tray layout for mixed and non-mixed geometries must be performed at this level, also. This problem could be complicated by having multiple batches of parts on one tray, each of which may have different geometries. A further complication is that deliveries to more than one workstation may be combined into one tray. It is not clear whether this latter problem can be resolved at the workstation level or must be passed up to the cell.

\subsubsection{Quality Control Workstations}

At these workstations, there is again the problem of sequencing tasks or activities. For the inspection workstation, this consists of determining which jobs to inspect and when, as well as which inspection activity to perform at which time. Once these have been determined, the decision about 
which probes to use to inspect must also be made. Then, after inspection has been completed, some parts will have to be scrapped and some will be candidates for rework. There are decision problems here that relate to the costs and benefits in each case. They must be resolved in light of due dates, priorities, and other existing jobs. Once these decisions are made, the rework parts must be put into a tray for further processing. There is a tray layout problem that must be solved. Again, some results from the facility layout literature may help here. It is also possible that an expert system may be useful in this process.

For the cleaning and deburring workstation, it is important to note that, since it consists of two robots, assigning tasks for it may very likely be non-trivial. It is possible that both robots will be required at the same time to perform one task, which is an additional complication.

As in the case of the other workstations, the quality control workstations are also responsible for coordinating activities of all subordinates.

\subsubsection{Machining Workstations}

At the machining workstation, the sequence of jobs to be done must be calculated, along with the coordination of activities of all subordinates. Conflicts of subordinate activity must be resolved, and if necessary, tasks reassigned. Assembly of parts may also be required at this level.

\subsection{Cell Level}

Basically, the cell must decide which workstation to use to perform a given operation. The problems at this level consist of scheduling tasks for the workstations in the cell, coordinating activities (parts and tool shipments) in support of that schedule, and coordinating delivery of parts and tools from one workstation to another. Coordination becomes a more crucial activity when there exist shared resources such as material handling workstation carts. If there are, there is a serious problem in coordination that must resolved. Even if there are no shared resources, there is still the problem of multimachine scheduling that must be confronted. Conflict resolution is also a responsibility of the cell. When conflicts arise at the workstation level, the cell must replan, reroute, and reschedule to overcome them.

\subsection{Shop Level}

The shop level has overall responsibility for inventory control, tool management, scheduling, sequencing, conflict resolution, cell creation, and preventive maintenance for all equipment in the shop. Also developed at this level is the master production schedule and the material requirements plans.

The actual responsibilities in these areas will depend on the configuration of the shop; principally whether it contains any shared resources, which for the shop means whether there are any virtual cells. In this case everything below the shop level is a shared resource and the problems for the shop level controllers are more complicated. 


\subsection{Facility Leve1}

The facility level has responsibility for the business and engineering functions which support the entire manufacturing plant. The mathematical techniques used in cost accounting, capital investment strategies, and many other business functions must be changed to include the impacts of automation [36]. In addition, new methods are needed to aid in the Group Technology classification and coding of parts from CAD data, the geometric modeling of parts, the decomposition of complex geometries into features that can be machined and inspected, and the design, revision, and verification of process plans.

$$
* * *
$$

In the next section, we discuss an implementation strategy under development at NBS, and the data requirements for it.

\section{AN INTEGRATION FRAMEWORK}

Work is underway at NBS to implement a framework in which integration of planning and control can be successfully carried out. This framework includes:

o a generic planning and control module which can be used at every level of the hierarchy,

o a process planning system to provide the technical data needed to plan and control activities, and

o a rich command/feedback structure to link one level of the hierarchy to the next.

These structures have been implemented at the bottom three levels of the AMRF hierarchy. The following sections provide a brief overview; more details can be found in the references provided.

\subsection{The Production Control Module}

A Production Control module [10] has been developed to plan and control activities within the AMRF. It is a generic module that has been implemented at the Cell, Workstation, and Equipment levels. This module is itself decomposed into a three level hierarchy: Production Manager (PM), Queue Manager (QM), and Dispatch Manager (DM). The planning functions are carried out by the PM and the QM; the control functions are assigned to the DM. The following sections provide a brief description of these levels.

\subsubsection{The Production Manager}

The Production Manager (PM) is the highest level within this module. It receives input from both its supervisor and the Queue Manager. Its supervisor provides a list of jobs to process and resources to allocate, while the Queue Manager provides feedback on the current status of all in- 
process work. Whenever a change is detected in the status of any job on that list or a new $\mathrm{job}$ is added to the existing list, the PM must retrieve all relevant data for that $\mathrm{job}$ and generate a real-time production plan. This production plan contains a list of the tasks assigned to each subordinate, precedence and coordination flags for each task, and a schedule of start and finish time for each task.

Commands are formulated from this plan using the command structure formats described below and passed to the appropriate Queue Manager. Coordination flags are used to change the status on jobs in one queue based on feedback about jobs in another queue. If everything is on schedule, then the plan is not altered. But, whenever a problem is encountered, the current plan must be updated to reflect the expected delays and the appropriate Queue Managers informed of any changes.

\section{1 .2 Queue Manager}

There is one Queue Manager (QM) for each subordinate controller. It receives a list of jobs from the Production Manager and feedback from the Dispatch Manager. The QM will resequence the queue to accomodate any changes in job status or the addition of new jobs. Whenever the status of any job changes or a new job is added, the QM passes the appropriate command information to the Dispatch Manager (DM) for eventual release to the subordinate. Whenever the DM sends feedback indicating that a job is completed the QM removes this entry from the queue and reports this up to the PM. The QM also updates timing information and reports this to the PM so that appropriate action can be taken to update the production plan.

\subsubsection{Disparch Manager}

There is one Dispatch Manager (DM) for each subordinate controller. The DM has a library of software routines that support the internal processing procedures derived from the process plan. The routines at this level define the way in which the DM, as a supervisor, controls the execution of tasks by the subordinate. It releases jobs to the Production Manager level of that subordinate and monitors the execution of those tasks to completion. Any problems that may result in delays in completion times are reported directly to the Queue Manager. Although it is theoretically possible to combine the QM and DM into a single job manager, that aggregation would unnecessarily increase the complexity of the QM.

\subsection{Data Requirements}

As was stated earlier, the AMRF hierchical control and planning structure is data-driven. There are basically two sources of data for the system: the process plans which describe what must be done, and the command/feedback process which provides information on what is being done. These are described next.

\subsubsection{Process Plans}

As indicated above, one source of input data to these production control modules is provided by the process planning system. An internal structure 
for these process plans has been identified and used at the bottom three levels of the AMRF hierarchy [9]. It specifies all of the technical information necessary to plan and control activities in an automated manufacturing environment. This includes not only the machining and robot handling instructions, but also workstation level operations and cell-level routing steps. Alternate processing sequences are also specified at each level. For each step in the plan, a work element description, precedence constraints, and estimated durations have been identified. These plans also provide an extended bill of materials that lists required tooling, fixtures, materials, processing systems, data, programs and/or plans that are required to complete the job. Finally, this information is provided in a uniform, consistent, error-free format which is compatible with the input requirements of the production control module.

\subsubsection{Command/Feedback Interface}

In addition to the interface with the Process Planning system, each control module must interface with one supervisor and one or more subordinates. The mechanism for this is the command and feedback structures described below $[7,10]$.

As noted earlier, the architecture under development provides for the planning and control of parallel activities. The command structure to support this capability is shown in Figure 4.

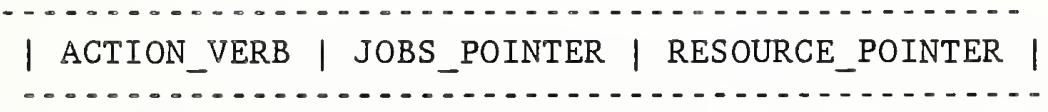

Figure 4. Command Interface Structure.

Each module will have a valid set of ACTION VERBs which initiate STARTUP, SHUTDOWN, EXECUTION, MAINTENANCE, and WĀIT sequences. The JOBS POINTER parameter is a pointer to a list of jobs in the database. Each entry in this list contains a job type flag (NEW or OLD), a job ID, a job action to be taken (PLAN, EXECUTE, CANCEL), priority, and timing information for scheduling purposes. The last field in this command structure is the RESOURCE_POINTER which is a reference to another table in the database. Each entry in this list refers to a specific resource request from a subordinate. It also contains the supervisor's response value (ACKNOWLEDGED, ALLOCATED, UNAVAILABLE, COMPLETED, etc.), and the expected time of availability.

The feedback structure to support these parallel activities mirrors the command structure and is shown in Figure 5 . 
OPERATIONAL | JOBS_STATUS | RESOURCE_REQUEST |

Figure 5. Feedback Interface Structure.

OPERATIONAL indicates the current operational status of the control module. JOBS_STATUS tracks the evolution of all jobs assigned to the module. RESOURCE_REQUEST reports ordinary or emergency run-time resource requests to the supervisor. Each of these three fields will be further divided into two subfields: CONDITION, and POINTER. The former consists of a simple set of ASCII responses and the latter is a pointer to a more detailed list in the database. This structure reduces the complexity involved in implementation by fixing the number of input parameters and by limiting the number of values that each of those parameters can take on.

In the next section, we discuss briefly some of the problems in managing this data in the real-time environment of the AMRF.

\section{REAL-TIME DATA MANAGEMENT}

The data management function is concerned with providing data to the manufacturing processes in a timely, accurate, and consistent manner. A new set of planning and scheduling problems is associated with the real-time management of data within these automated manufacturing facilities. These problems can be divided into two major categories: Data Administration and Data Communication.

\subsection{Data Administration}

A recent report [11] suggests that centralized data collection and administration will not be sufficient to satisfy the data demands in the factory of the future. As an alternative to the centralized data administration approach, NBS researchers have been developing a distributed data administration system called IMDAS [11]. Although it is logically centralized, IMDAS provides for the distributed administration of physically distributed data.

The desire to distribute data physically across the facility is prompted by the time-criticality factor involved in certain data requests, particularly at the equipment level of the planning and control hierarchy. Several questions must be addressed concerning the optimal selection of local data storage devices and their database management capabilities, the actual allocation of the master copy of each data item to a particular device, and the number and location of the copies of that data item.

The physical distribution of data also has a significant impact on the administration of that data. Typical administrative functions include satisfying all data requests, maintaining all data dictionaries, ensuring that the data is accurate, and supervising all concurrency and consistency checks. A three-level, tree-like architecture has been defined to carry out these functions. Each level will have a queue of jobs to perform. Each job 
will consist of some tasks to be carried out at that level and, possibly, some tasks to be executed by one or more modules at the next lower or next higher level. This leads to some scheduling and sequencing problems at each level which are different from those described in the planning and control hierarchy (see section 4). They are complicated by the difficulty involved in a) determining the time required to complete a task, b) obtaining a "due date" for a given task, and, c) coordinating the parallel activities at all three levels which may be involved in the completion of a single complex data request.

Little is known about approaches to solving these problems.

\subsection{Data Communication}

The transfer of information between computer processes in an automated manufacturing environment will be managed by a Data Communication System (DCS). This implies that processes do not communicate directly with one another; rather, they simply make information available. It is the DCS's repsonsibility to deliver that information to those processes that require it, at the time they require it. The protocols for accomplishing this data transfer are being specified in the Manufacturing Automation Protocol (MAP) standards [12].

It is likely that many of the techniques used to design and manage computer networks [35] will be applicable here. However, the introduction of the "virtual cell" notion (see section 2.3.3) will have a significant impact on the both the design and real-time administration of the DCS. The difficulties result from the need to "disconnect and connect" processes, and therefore origin-destination pairs and paths, from one another in real-time. To date, these issues have not been addressed.

\section{CONCLUSIONS AND FUTURE WORK}

Two major areas related to real-time production planning for automated manufacturing systems have been addressed in this paper. First, these planning problems have been identified and partitioned into five layers to match the AMRF control hierarchy under development at NBS. Second, a framework has been proposed which provides a means for integrating planning and control into a single hierarchy. That framework consists of a generic production control module which can be used at every level in the hierarchy, a process planning system and command/feedback structures to provide data to those modules, and a data management system to store, update, and transfer that data in a timely and accurate manner.

Future research will focus on the development of solution techniques for the decision problems described in the preceding sections. This research will be conducted in three concurrent phases. First, we must determine the information, both qualitative and quantitative, required to solve each problem. Next, we must find efficient structures for representing that information. Finally, we will attempt to marry techniques from Operations Research and Artificial Intelligence to solve each problem. 
We believe that this work fills an important gap in the literature, provides a fundamental contribution to the field, and will provide the groundwork for more fruitful research in this area.

\section{REFERENCES}

1. Simpson, J., Hocken, R., and Albus, J., "The Automated Manufacturing Research Facility of the National Bureau of Standards", Journal of Manufacturing Systems, Vol.1, 1982, pp. 17-31.

2. McLean, C., Mitchel1, M., Barkmeyer, E., "A Computing Architecture for Small Batch Manufacturing, "IEEE Spectrum, May, 1983.

3. Albus, J., Barbera, A., and Nagel, N., "Theory and Practice of Hierarchical Control", Proceedings of 23rd IEEE Computer Society International Conference, September, 1981.

4. Albus, J., et al., "A Control System for an Automated Manufacturing Research Facility", Robots 8 Conference and Exposition, Detroit, MI, June 4, 1984.

5. Barbera, A., Fitzgerald, M. and Albus, J., "Concepts for a Real-Time Sensory-Interactive Control System Architecture", Proceedings of the 14th Southeastern Symposium on System Theory, April, 1982.

6. Mclean, C., Bloom, H., Hopp, T. "The Virtual Manufacturing Cell", Proceedings of Fourth IFAC/IFIP Conference on Information Control Problems in Manufacturing Technology, NBS, October, 1982.

7. Jones, A. and Mclean, C., "A Cell Control System for the AMRF", Proceedings of the 1984 ASME International Computers in Engineering Conference, Las Vegas, Nevada, $12-15$ August, 1984.

8. Jones, A., and Mclean, C.," A Proposed Hierarchical Control Model for Automated Manufacturing Systems", Journal of Manufacturing Systems, Volume 5, No. 1, 15-25, 1986.

9. Mclean, C., "Process Planning for Distributed Manufacturing Control", Working Paper, National Bureau of Standards, Gaithersburg, MD, 20899.

10. Jones, A., and Mclean, C., "A Production Control Module for the AMRF", Proceedings of the ASME International Conference on Computers in Mechanical Engineering, August, 1985.

11. Barkmeyer, E., et a1., "Distributed Data Management Architecture for Computer Integrated Manufacturing", Technical Report NBSIR 86-3312, National Bureau of Standards, Gaithersburg, MD, January 1986.

12. Data Processing - Open Systems Interconnection - Basic Reference Model, North Holland Publishing Company, 1981, pp. 81-118. 
13. Baker, K. R., Introduction to Sequencing and Scheduling, John Wiley, New York, 1974.

14. Conway, R. W., Maxwell, E. A., Miller, K. W., Theory of Scheduling, Addison-Wesley, Reading, Massachusetts, 1967.

15. Elmaghraby, S. E., (ed.), Symposium on the Theory of Scheduling, Springer-Verlag, Berlin, 1973.

16. Gershwin, S., "An Approach to Hierarchical Production Planning and Scheduling", Proceedings of the Symposium on Real-time Optimization in Automated Manufacturing Facilities, National Bureau of Standards, Gaithersburg, MD, January 21-22, 1986.

17. O'Grady, P. and Menon, U., "A Hierarchy of Intelligent Scheduling and Control for Automated Manufacturing Systems", Proceedings of the Symposium on Real-time Optimization in Automated Manufacturing Facilities, National Bureau of Standards, Gaithersburg, MD, January 21 $22,1986$.

18. Akella, R., Choomg, Y., Gershwing, S., "Performance of Hierarchical Scheduling Policy", IEEE Transactions on Components, Hybrid and Manufacturing Technology, CHMT-7, pp. 225-240, 1984.

19. Bitran, G. R., Hax, A. C., "On the Design of Hierarchical Production Planning Systems", Decision Sciences, 8, pp. 28-54, 1977.

20. Bitran, G. R., Haas, E. A., Hax, A. E., "Hierarchical Production Planning: A Single Stage System", Operations Research, 29, pp. 717-743, 1981.

21. Bitran, G. R., Haas, E. A., Hax, A. E., "Hierarchical Production Planning: A Two Stage System", Operations Research, 29, pp. 232-251, 1982.

22. Davis, W. J., "Decision Making and Control Hierarchies for Produciton Systems", Technical Report No. 145, PLAIC, Purdue University, West Lafayette, IN, 1984.

23. Shaw, M., "A Two Level Planning and Scheduling Approach for Computer Integrated Manufacturing", Proceedings of the Symposium on Real-time Optimization in Automated Manufacturing Facilities, National Bureau of Standards, Gaithersburg, MD, January 21-22, 1986.

24. Raman, N., "A Survey of the Literature on Production Scheduling as it Pertains to Flexible Manufacturing Systems", Technical Report NBS-GCR 85-499, National Bureau of Standards, Gaithersburg, MD, 1986.

25. Sen, T., and Gupta, S. K., "A State-of-the-Art Survey of Static Scheduling Research Involving Due Dates", Omega, 12, No. 1, pp. 63-76, 1984. 
26. Graves S., "A Review of Production Scheduling", Operations Research, 29, $646.675,1981$.

27. Graham, R. L., et al., "Optimization and Approximation in Deterministic Sequencing and Scheduling: A Survey", Annals of Discrete Mathematics, 5 , pp. $288-326,1979$.

28. Lawerance, S. R., and Morton, T. R., PATRIACH: Hiexarchical Production Scheduling", Proceedings of the Symposium on Real-time Optimization in Automated Manufacturing Facilities, National Bureau of Standards, Gaithersburg, MD, January 21-22, 1986.

29. Fox, M. Constraint-Directed Search: a case study in job shop scheduling, Doctoral Dissertation, Carnegie-Mellon Universtiy, 1983.

30. Steffen, M. S., and Greene, T. J., "Hierarchies of Sub-Periods in Constraint Directed Scheduling", Proceedings of the Symposium on Realtime Optimization in Automated Manufacturing Facilities, National Bureau of Standards, Gaithersburg, MD, January 21-22, 1986.

31. Wysk, R., Wu, S., Yang, N., "A Multi-Pass Expert Control System for Flexible Manufacturing Systems", Proceedings of the Symposium on Realtime Optimization in Automated Manufacturing Facilities, National Bureau of Standards, Gaithersburg, MD, January 21-22, 1986.

32. Chiodini, V., "A Knowledge Based System for Dynamic Manufacturing Replanning", Proceedings of the Symposium on Real-time Optimization in Automated Manufacturing Facilities, National Bureau of Standards, Gaithersburg, MD, January 21-22, 1986.

33. Maley, J., Ruiz-Mier, S., and Solberg, J., "Dynamic Optimization in Automated Manufacturing - A Knowledge Integrated Approach", Proceedings of the Symposium on Real-time Optimization in Automated Manufacturing Facilities, National Bureau of Standards, Gaithersburg, MD, January 21 $22,1986$.

34. Jackson, R., and Jones, A., (eds.), Proceedings of the Symposium on Real-time Optimization in Automated Manufacturing Facilities, National Bureau of Standards, Gaithersburg, MD, January 21-22, 1986.

35. Kleinrock, L., Queueing Systems Volume II: Computer Applications, John Wiley, New York, 1976.

36. Eiler, R., "Cost Accounting Faces Automation", Managing Automation, Vol. 1, No.1, pp. 25-29, 1986. 
The NBS Automated Manufacturing Research Facility is partially supported by the Navy Manufacturing Technology Program.

This is to certify that the article written above was prepared by United States Government employees as part of their official duties and is therefore a work of the U.S. Government and not subject to copyright. 
NBS.ll

U.S. DEPT. OF COMM.

1. PUBLICATION OR REPORT NO.

BIBLIOGRAPHIC DATA

SHEET (See in struction S)

NBS-IR 87-3511

2. Performing Organ. Report No o 3. Publication Date

FEBRUARY 1987

4. TITLE AND SUBTITLE

Hierarchical Decision-Making in the Factory of the Future

5. AUTHOR(S)

Richard H.F. Jackson, Albert W. T. Jones

6. PERFORMING ORGANIZATION (If joint or other than NBS, see in structions)

7. Contraed/Grant No.

NATIONAL BUREAU OF STANDARDS

DEPARTMENT OF COMMERCE

WA.SHINGTON, D.C. 20234

9. SFONSORING ORGANIZATION NAME AND COMFIETE ACCRESS (Street, CIT, StOT, ZIR)

8. Type of Report \& Period Covered

10. SUPPLEMENTARY NOTES

Document describes a computer program; SF-185, FIPS Software Summary, is attached.

11. ABSTRACT (A 200-word or less factual summary of most significant information. If document includes a significant bibliography or literature survey. mention it here)

A major manufacturing research facility is being established at the National Bureau of Standards. The Automated Manufacturing Research Facility will address the standards and measurement needs for the factory of the future. A five-layer hierarchical control architecture is under development to manage all production and support activities within the facility. The proper execution of many of these activities requires the solution to one or more optimization problems.

This paper describes a hierarchical planning architecture and the decision-making problems that exist at each level within that architecture.

12. KEY WORDS (Six to twelve entries; alphabetical order; capitalize only proper names; and seporate key words by semicolons) Automated Manufacturing; Factory Model; flexible manufacturingl Hierarchical control; real-time; optimization, scheduling; routing

13. AVAILABILITY

Unlimited

For Official Distribution. Do Not Release to NTIS

Order From Superintendent of Documents, U.S. Government Printing Office, Washington. D.C. 20402.

[. Order From National Technical Information Service (NTIS). Springfield, VA. 2216I
14. NO. OF PRINTED PAGES

24

15. Price 



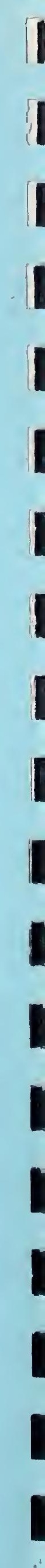

